\title{
Case Study: Potential Drug Usage In The Workplace
}

John J. Lucas, Purdue University Calumet, USA

\begin{abstract}
This HRM case focuses on potential drug usage in the workplace and the appropriate steps to address this issue. This case is based upon an actual event that occurred in production plant of a Fortune 500 company. The case study can be used for any undergraduate or graduate level human resource management class.
\end{abstract}

Keywords: Workplace Drug Use; Drug Usage

\section{BACKGROUND}

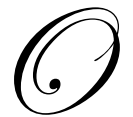

$\mathrm{n}$ a frigid mid-December evening, a mechanical maintenance employee, who was a member of the International Brotherhood of Electrical Workers (IBEW), was given a work assignment to pick up seventy hot meals from a local restaurant. He was given a company car to pick up and deliver the meals. These meals were to be distributed to the employees who were working overtime at the production plant. After an hour elapsed, a plant supervisor became very worried since the mechanical maintenance worker hadn't returned with the meals and the restaurant was only few miles away from the plant. The supervisor then called the restaurant and was informed that the worker had indeed picked up the hot meals. After a couple of hours elapsed and still no overtime meals for the workers, the supervisor reordered seventy meals and assigned another worker to pick up the hot meals. This time the meals were successfully delivered without incident. A few more hours passed, and there was still "no call-no show" from the mechanical maintenance worker. Finally, early in the morning, the mechanical maintenance employee returned to the plant with no company car and no meals.

Upon his returned, the employee was questioned by the shift supervisor and the human resources department, with a union steward present. The mechanical maintenance worker explained that he had made a quick stop to buy a piece of pizza because he was really hungry. He had left the company car running, with the keys inside, and after he ate the slice of pizza, which only took a few minutes, he discovered, upon returning to the parking lot, that someone had stolen the company car. During this questioning of the mechanical maintenance worker, the plant manager received a call that the company car had been found in front of a house in a residential area close to the plant. The car had been crashed into a large tree in front of this house. With this new information, the worker was requested to submit to a drug test, based upon this as the possible cause of the car accident. Initially, the worker refused, but after a few more hours, he agreed to a drug test. The worker was driven home by a shift supervisor and told not to return to the plant until the drug test results were determined. After a couple days, the drug test result was confirmed to be positive by the Medical Review Officer (MRO) at the company.

\section{Questions for the Case Study}

1. Should the mechanical maintenance worker be terminated for use of drugs on company property? If not, what is the appropriate discipline for the worker?

2. What if the worker tried to alter the drug test, what is the appropriate action that should be taken by the company?

3. What possible recourse, if any, is available to the mechanical maintenance employee, if he regarded the discipline or discharge to which he was subjected as excessive or without "just cause?" 
4. What if the drug test result had been negative, what discipline, if any, should have been given to the employee for his failure to deliver the overtime meals and having a car accident?"

5. What if the drug test result had been diluted (tested neither positive nor negative), what is the appropriate action that should be taken by the company.

6. What if the employee entered a drug rehabilitation facility thru the company's EAP (Employee Assistance Program), is the employee exempt from discipline or discharge for a positive drug test?

7. Is the company required to negotiate a drug/alcohol policy with the union? If not, can the company unilaterally implement a drug/alcohol policy to fulfill its obligation of a drug/alcohol free workplace?

8. What further actions can the company undertake to reinforce their desire to remain drug /alcohol free in the workplace?

\section{INSTRUCTOR'S NOTES}

This case provides an interesting examination of the potential usage of drugs in the workplace and the appropriate course of action, if a drug incident should occur in the workplace. The case can be used in any undergraduate or graduate level human resource management class. It is designed to be conducted as a group assignment or general class discussion within one class hour.

\section{AUTHOR INFORMATION}

Dr. John J. Lucas is a Professor at Purdue University Calumet and teaches a variety of human resource management courses. He earned his Master of Science in Industrial Relations (MSIR) and Ph.D. degrees from Loyola University Chicago. His research interests are in the areas of labor relations, employee benefits, and health education. He is also a graduate of Purdue University Calumet. E-mail: jlucas@purduecal.edu. 